\title{
Short communication: Physicochemical and antioxidant properties of Cheddar-type cheese fortified with Inula britannica extract
}

\author{
N.-K. Lee, ${ }^{*}$ R. K. C. Jeewanthi, ${ }^{*}$ E.-H. Park, ${ }^{*}$ and H.-D. Paik ${ }^{*} \dagger^{1}$ \\ *Department of Food Science and Biotechnology of Animal Resources, Konkuk University, 120 Neungdong-ro, Gwangjin-gu, \\ Seoul 143-701, Korea \\ †Bio/Molecular Informatics Center, Konkuk University, 120 Neungdong-ro, Gwangjin-gu, Seoul 143-701, Korea
}

\section{ABSTRACT}

Cheddar-type cheese was fortified with the antioxidant Inula britannica flower extract (IBE). Cheddartype cheeses manufactured with varying concentrations of $\operatorname{IBE}(0,0.25,0.5,0.75$, and $1 \% \mathrm{wt} / \mathrm{vol})$ were analyzed during storage at $4^{\circ} \mathrm{C}, 0,1,2$, and 3 wk after production. Higher IBE concentrations resulted in higher protein and ash contents, with a concomitant decrease in $\mathrm{pH}$, total solid, and fat content relative to the unfortified control cheese. The total phenolic content also increased with IBE concentration, but decreased over longer storage periods. The antioxidant activities of the cheeses, determined as 2,2-diphenyl-1-picrylhydrazyl (DPPH) free-radical scavenging activity and ferric thiocyanate assay results, increased proportionally to the total phenolic content. The highest antioxidant effect was observed in the 1\% IBE-fortified cheese, showing 79 and $86 \%$ antioxidant effects in the DPPH and ferric thiocyanate assays, respectively. At the 1-wk time point, the 5 cheese preparations underwent sensory evaluation for odor, taste, texture, color, and overall quality, determined using a descriptive analysis by a trained panel $(\mathrm{n}=20)$. The addition of IBE resulted in some increases in extract odor and taste. Overall, IBE showed good potential as an antioxidant supplement for dairy products.

Key words: Inula britannica, Cheddar-type cheese, physicochemical property, antioxidant activity

\section{Short Communication}

The flower of Inula britannica has been used as a traditional herbal medicine for the treatment of digestive disorders, inflammation, and bronchitis (Bai et

Received June 9, 2015

Accepted September 11, 2015.

${ }^{1}$ Corresponding author: hdpaik@konkuk.ac.kr al., 2005), and its use is approved by the Korea Food and Drug Administration (Lee et al., 2013). The antioxidant activities of the I. britannica flower are mainly attributed to its phenolic content, which is reported to consist mainly of luteolin, diometin, chrysoeriol, kaempferol, quercetin, 6-hydroxyluteolin-6-methyl ether, spinacetin, and eupatin (Chung et al., 1999; Park et al., 2000; Bai et al., 2005). The I. britannica flower has mainly been used in medicinals, cosmetics, beverages, and natural preservatives (Seo et al., 2002; Kim et al., 2011). However, I. britannica flower has not been used in dairy products.

Cheese is a solid milk concentrate that consists mainly of proteins. During the cheese making process, curd is generally made via the enzymatic coagulation of milk casein (Robitaille et al., 2004). Cheddar-type cheese, especially young Cheddar-type cheese, has been analyzed with respect to texture, performance, and flavor, in a study that focused on functional properties (Hassan et al., 2007). In South Korea, mozzarella is the most popular cheese type with a $60 \%$ value share in 2012, followed by Cheddar with a $23 \%$ value share (Kansendossier Zuid, 2013). The reported antioxidant activity of cheese is derived from the milk peptides released from casein by lactic acid bacteria (Gupta et al., 2009). Histidine and proline are known to have a lipoprotein-peroxidation inhibitory effect, whereas tyrosine and tryptophan have shown scavenging capability for the 2,2-azinobis (3-ethylbenzothiazoline)-6-sulfonic acid (ABTS+) radical.

Phenolic compounds have been proposed for use as nutritional ingredients to improve the functional properties of milk and dairy products. Green tea extract (Giroux et al., 2013), red ginseng extract (Jung et al., 2015), catechin (Rashidinejad et al., 2015), grape extract (Han et al., 2011a; da Silva et al., 2015), and dehydrated cranberry powder (Han et al., 2011a) have all been used as enrichment ingredients for their antioxidant effects. Although cheese contains small amounts of phenolic compounds, their effect is limited due to their low antioxidant activity (Han et al., 2011b). This 
is because the interaction of phenolic compounds and proteins can be limited by the $\mathrm{pH}$, molar ratio, and molecular properties of the polyphenols (Gad and ElSalam, 2010).

Cheddar-type cheese is usually ripened for $3 \mathrm{mo}$, but low-priced young cheese is popular in Quebec, Canada (St-Gelais et al., 2009). Cheddar-type cheese enriched with green tea extract has been studied over a 29-d storage period (Giroux et al., 2013). The objective of the present study was to produce Cheddar-type cheeses fortified with $I$. britannica flower extracts (IBE) and evaluate their physicochemical properties, antioxidant activities, and sensory characteristics. In addition, the effect of storage time on the antioxidant effect was investigated over 3 wk at $4^{\circ} \mathrm{C}$.

Inula britannica flowers were purchased from traditional medicinal markets in Seoul, Korea, and commercially available milk was used (Seoul Dairy Co., Seoul, Korea). Liquid rennet (Naturen) was obtained from Chr. Hansen, Melbourne, Australia, and a commercial starter culture (ABT-L) was purchased from Chr. Hansen, Hørsholm, Denmark. The starter culture contained a mix of Lactobacillus acidophilus, Bifidobacterium longum, and Streptococcus thermophilus. All other reagents used were of analytical grade.

Twenty-gram samples of the dried, ground I. britannica flowers were mixed with $200 \mathrm{~mL}$ of water and incubated at $60^{\circ} \mathrm{C}$ for $24 \mathrm{~h}$. The extracts were then filtered using Whatman No. 2 filter paper, freeze-dried, and stored at $-20^{\circ} \mathrm{C}$ until use.

Cheddar-type cheese was made from whole milk according to the Codex Standard 263 (Codex, 2010). Preheated milk $\left(32^{\circ} \mathrm{C}, 10 \mathrm{~L}\right)$ was mixed with $\operatorname{IBE}(0,0.25$, $0.5,0.75$, and $1 \% \mathrm{wt} / \mathrm{vol}$ ), and starter culture inoculum was then added at $0.2 \%$ concentration. Ripening was allowed to proceed until the $\mathrm{pH}$ had dropped to 5.2 to 5.4. Then, $0.01 \%$ rennet was added and ripening was continued at $37^{\circ} \mathrm{C}$ to allow for coagulation. After coagulation, the curd was cut into $1.5-\mathrm{cm}^{3}$ cubes and heated in its whey to a temperature of $37^{\circ} \mathrm{C}$. The curd was then separated from the whey and cut into blocks that were turned and progressively piled, keeping the curd warm $\left(37-39^{\circ} \mathrm{C}\right)$, which results in the curd becoming compressed, smooth, and elastic. After cheddaring, the curd was milled. When the $\mathrm{pH}$ reached 5.2, the curd was molded without salting to protect its antioxidant properties. The Cheddar-type cheeses fortified with $0.25,0.5,0.75$, and $1 \% \mathrm{IBE}$ were designated as A, B, C, and $\mathrm{D}$, respectively. Unfortified ( $0 \% \mathrm{IBE})$ cheese served as the control. For determination of the total phenolic contents and antioxidant activities, all cheeses were melted in water to form solutions at a concentration of $10 \%$ (wt/vol).
The total solids, protein, fat, and ash contents were measured according to the AOAC International (2000) methods. Grated cheese was analyzed for its protein and fat levels using the Kjeldahl method and the modified Mojonnier (AOAC International, 2000) method, respectively. All chemical measurements were done in triplicate immediately after production of the cheeses.

The total phenolic content of the samples was determined by the Folin-Ciocalteu method (Yoon et al., 2015). One-hundred-microliter aliquots of $10 \%$ cheese solution were mixed with $2 \mathrm{~mL}$ of $2 \%$ sodium carbonate solution and left for $3 \mathrm{~min}$ at room temperature. Subsequently, $0.1 \mathrm{~mL}$ of $50 \%$ Folin-Ciocalteu reagent (Sigma-Aldrich Co., Steinheim, Germany) was added and the mixture was incubated for $30 \mathrm{~min}$ at room temperature. The absorbance of the reaction mixture was measured at $750 \mathrm{~nm}$ using a spectrophotometer (Optizen $2120 \mathrm{UV}$; Mecasys Co., Ltd., Daejeon, Korea). The total phenolic content was calculated on a standard curve constructed using gallic acid (0-250 mg/L; Sigma-Aldrich), and was expressed as milligrams of gallic acid equivalents per gram (mg of GAE/g).

For measurement of antioxidant activity, the 2,2-diphenyl-1-picrylhydrazyl (DPPH) radical-scavenging activity and ferric thiocyanate (FTC) assays were performed.

The DPPH radical-scavenging activity of the cheeses was determined using the method of Savikin et al. (2009). Two hundred microliters of $10 \%$ cheese sample solution was mixed with $1 \mathrm{~mL}$ of $100 \mu M \mathrm{DPPH}$ solution. After a 15-min incubation, the absorbance at 517 $\mathrm{nm}$ was measured using a spectrophotometer. Butylated hydroxytoluene at $1 \mathrm{mg} / \mathrm{mL}$ concentration was used a positive control. The DPPH radical-scavenging activity was calculated from the following formula:

$$
\begin{gathered}
\text { DPPH radical-scavenging activity }(\%)= \\
{[1-(\text { sample absorbance at } 517 \mathrm{~nm} / \text { control }} \\
\text { absorbance at } 517 \mathrm{~nm})] \times 100 .
\end{gathered}
$$

The antioxidant activity of the Cheddar-type cheeses was measured by FTC using a procedure modified from Lee et al. (2004). Aliquots of $10 \%$ solutions of each cheese type were subjected to analysis. Vitamin C at $1 \mathrm{mg} / \mathrm{mL}$ concentration was used as a positive control. The reaction mixture, comprising $100 \mu \mathrm{L}$ of sample, 0.2 $\mathrm{mL}$ of linoleic acid solution $(25 \mathrm{mg} / \mathrm{mL})$ in ethanol, 0.4 $\mathrm{mL}$ of $40 \mathrm{~m} M$ phosphate buffer, and $0.2 \mathrm{~mL}$ of distilled water, was incubated at $37^{\circ} \mathrm{C}$ in the dark for $72 \mathrm{~h}$. Thereafter, $0.1-\mathrm{mL}$ aliquots were diluted with $4 \mathrm{~mL}$ of $70 \%$ ethanol and $0.1 \mathrm{~mL}$ of $30 \%$ ammonium thiocyanate was added. This was followed by the addition of 
Table 1. Chemical composition (means $\pm \mathrm{SD}$ ) of Cheddar-type cheeses fortified with Inula britannica flower extract $(\mathrm{IBE})^{1}$

\begin{tabular}{|c|c|c|c|c|c|}
\hline Item & Control & $\mathrm{A}$ & B & $\mathrm{C}$ & $\mathrm{D}$ \\
\hline$\overline{\mathrm{TS}(\%)}$ & $37.77 \pm 0.27^{\mathrm{a}}$ & $37.41 \pm 0.09^{\mathrm{a}}$ & $37.03 \pm 4.79^{\mathrm{a}}$ & $36.92 \pm 0.06^{\mathrm{a}}$ & $35.79 \pm 0.98^{\mathrm{a}}$ \\
\hline Protein (\%) & $23.72 \pm 0.27^{\mathrm{a}}$ & $24.22 \pm 0.62^{\mathrm{a}}$ & $27.31 \pm 1.89^{\mathrm{a}}$ & $27.50 \pm 1.13^{\mathrm{a}}$ & $28.33 \pm 1.84^{\mathrm{a}}$ \\
\hline Fat $(\%)$ & $20.25 \pm 0.36^{\mathrm{a}}$ & $20.37 \pm 0.03^{\mathrm{a}}$ & $19.36 \pm 2.11^{\mathrm{a}}$ & $18.75 \pm 2.34^{\mathrm{a}}$ & $18.56 \pm 2.37^{\mathrm{a}}$ \\
\hline $\mathrm{pH}$ & $5.10 \pm 0.01^{\mathrm{b}}$ & $4.96 \pm 0.04^{\mathrm{a}}$ & $4.95 \pm 0.05^{\mathrm{a}}$ & $4.93 \pm 0.1^{\mathrm{a}}$ & $4.90 \pm 0.08^{\mathrm{a}}$ \\
\hline
\end{tabular}

${ }^{\mathrm{a}-\mathrm{c}}$ Averages within a row with different superscript letters are significantly different at $P<0.05$.

${ }^{1}$ Control = Cheddar-type cheese made from unfortified milk; $\mathrm{A}=$ Cheddar-type cheese made from $0.25 \%$ IBE-fortified milk; $\mathrm{B}=$ Cheddar-type cheese made from $0.5 \%$ IBE-fortified milk; $\mathrm{C}=$ Cheddar-type cheese made from $0.75 \%$ IBE-fortified milk; $\mathrm{D}=\mathrm{Cheddar-type} \mathrm{cheese} \mathrm{made} \mathrm{from}$ $1 \%$ IBE-fortified milk.

$20 \mathrm{mM} \mathrm{FeCl} 2$ in $3.5 \% \mathrm{HCl}$. The absorbance of the red color was measured at $500 \mathrm{~nm}$ against a blank that used water instead of sample. Antioxidant activity was calculated from the following formula:

antioxidant activity $(\%)=[1-($ sample absorbance

at $500 \mathrm{~nm} /$ blank absorbance at $500 \mathrm{~nm})] \times 100$.

Sensory evaluation of fresh Cheddar-type cheeses was performed by a panel of 20 trained assessors (10 males and 10 females) recruited and screened according to accepted international standards (ISO/DIS 13299:1998; ISO, 1998). The cheeses were cut into $2 \mathrm{~cm} \times 2 \mathrm{~cm}$ blocks, and each sample was labeled with a random 5 -digit number and served at room temperature. Assessment scales for 10 attributes were displayed for scoring, and were anchored by verbal descriptors at each end, with the left side of the scale corresponding to the lowest intensity, extremely unlike, or absence (value 1) of the attribute, and the right side corresponding to the highest intensity, extremely like, or perfect condition (value 10) of the attribute.

The results of this study are expressed as the mean \pm standard deviation of the treatments carried out in triplicate, and were analyzed by one-way ANOVA, Duncan's multiple range test, and Pearson correlation. The probability level for statistical significance was set at $P<0.05$. The SPSS version 18 software (Chicago, IL) was used for all analyses.

The compositions of the IBE-fortified cheddar-type cheeses are presented in Table 1 . The addition of IBE did not have a significant effect on TS or fat $(P>$ $0.05)$. However, the protein content, ash content, and $\mathrm{pH}$ were significantly affected $(P<0.05)$. The control cheese contained $37.77 \%$ total solids, $23.72 \%$ protein, $22.02 \%$ fat, and $0.76 \%$ ash, and had a $\mathrm{pH}$ of 5.1 . Among IBE-fortified cheeses, the total solids, fat contents, and $\mathrm{pH}$ decreased with an increase in IBE content, whereas the protein and ash contents increased. The IBE itself contained $91.47 \%$ total solids, $6.55 \%$ protein, $3.26 \%$ fat, and $17.65 \%$ ash. The correlation coefficients between protein and addition of IBE, and between ash and addition of IBE were $0.569(P<0.05)$ and $0.844(P<$ $0.01)$, respectively. This might be due to the addition of IBE having affected the water-holding capacity of the cheese. The IBE seemed to promote the contraction of the cheese matrix and the expulsion of whey, reducing the quantity of entrapped water in the protein network. In agreement with this, phenolic compounds have been found to decrease the curd moisture content (Han et al., 2011a). Moreover, the protein recovery in cheese was consistent with the results obtained using green tea extract (Giroux et al., 2013) and grape extract (da Silva et al., 2015). The increase in protein was likely due to interactions between the polyphenolic compounds and milk protein, resulting in cross-linking or precipitation (O'Connell and Fox, 2001).

Phenolic compounds are important plant constituents because of their antioxidant effect. The total phenolic contents of the IBE-fortified cheeses were calculated using the gallic acid standard equation, and the data are presented in Figure 1A. The total phenolic content of $0.1 \mathrm{IBE}$ in water was $82.95 \mathrm{mg}$ of $\mathrm{GAE} / \mathrm{g}$. At 0 wk of storage, the total phenolic contents of cheese fortified with $0,0.25,0.5,0.75$, and $1 \%$ IBE were $44.43,54.79$, $58.75,59.52$, and $70.82 \mathrm{mg}$ of GAE/g, respectively, indicating that the total phenolic contents increased with the addition of IBE $(\mathrm{r}=0.680, P<0.01)$. However, the total phenolic contents decreased with longer storage periods $(\mathrm{r}=-0.703, P<0.01)$, where the reduction was greater for the cheese fortified with $1 \%$ IBE than with $0.1 \%$ IBE in water. This decrease was due to the increased interaction between phenolic compounds and proteins (Gad and El-Salam, 2010).

The dietary intake of natural antioxidants is correlated with decreased risks for various diseases such as inflammation, cancer, and cardiovascular diseases (Yoon et al., 2015). The antioxidant activity was assessed here using 2 methods, owing to diversity in the antioxidant mechanisms. The radical-scavenging effect and the lipid-peroxidation inhibitory effect were dem- 


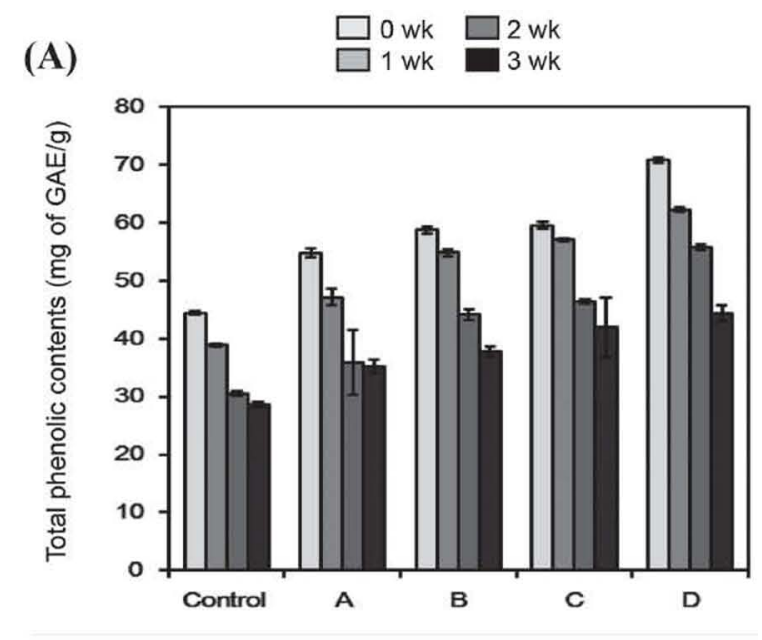

(B)

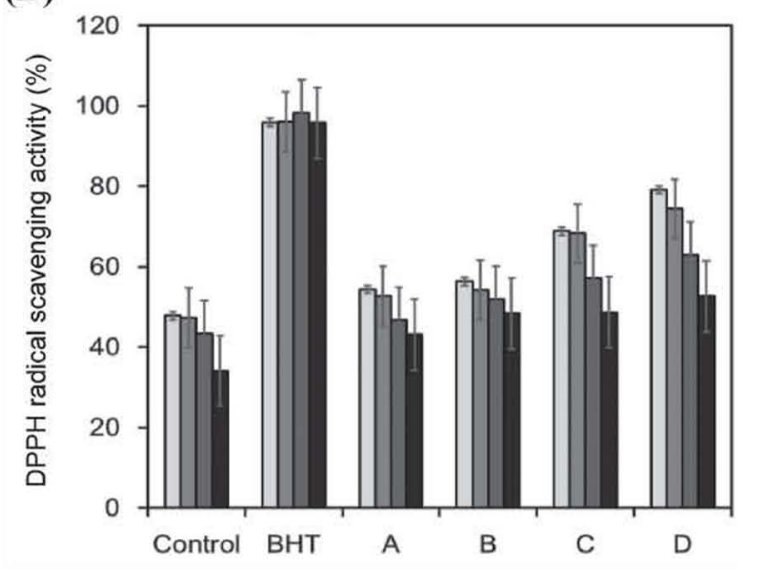

(C)

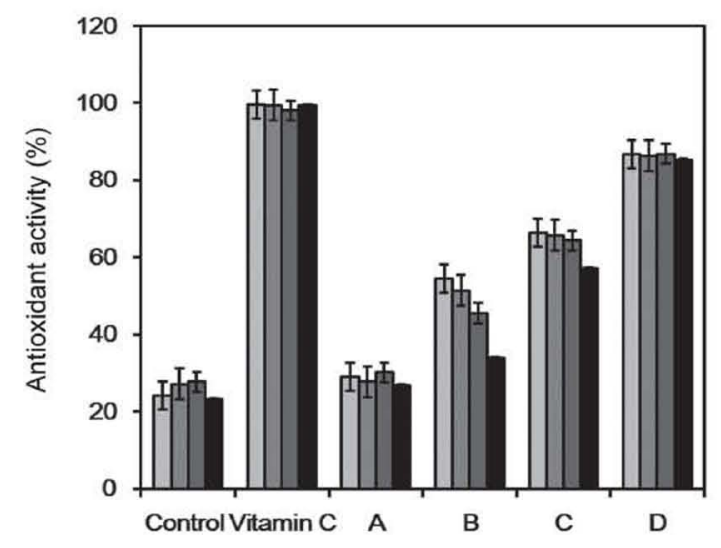

Figure 1. Antioxidant activity in Cheddar-type cheeses fortified with Inula britannica flower extract (IBE). (A) Total phenolic contents, (B) 2,2-diphenyl-1-picrylhydrazyl (DPPH) radical-scavenging activity, and (C) antioxidant activity by the ferric thiocyanate method. Control, Cheddar-type cheese made from unfortified milk; butylated hydroxytoluene (BHT) or vitamin C, positive control; A, Cheddartype cheese made from $0.25 \%$ IBE-fortified milk; B, Cheddar-type cheese made from $0.5 \%$ IBE-fortified milk; C, Cheddar-type cheese made from $0.75 \%$ IBE-fortified milk; D, Cheddar-type cheese made from 1\% IBE-fortified milk; white, 0 wk; light gray, 1 wk; dark gray, 2 wk; black, 3 wk. GAE = gallic acid equivalents. onstrated using the DPPH radical-scavenging assay and the FTC assay, respectively.

The DPPH radical-scavenging assay shows the hydrogen-donating activity of the fortified cheese (Figure 1B). Increasing the concentration of IBE resulted in increased DPPH radical-scavenging activity $(\mathrm{r}=0.773$, $P<0.01$ ). At 0 wk of storage, the DPPH radical-scavenging activities of the cheeses fortified with $0,0.25$, $0.5,0.75$, and $1 \%$ IBE were $47.76,53.34,56.32,68.81$, and $79.07 \%$, respectively. However, the DPPH radicalscavenging activity decreased with longer storage periods $(\mathrm{r}=-0.559, P<0.05)$. In addition, the correlation coefficient between total phenolic content and DPPH radical-scavenging activity was $0.927(P<0.01)$.

The antioxidant activities of the Cheddar-type cheeses determined with the FTC assay are shown in Figure $1 \mathrm{C}$. This assay demonstrates the reducing power and metal-chelating capability of the fortified cheese. The IBE-fortified cheeses had a higher antioxidant activity than control cheese $(\mathrm{r}=0.960, P<0.01)$. At 0 wk of storage, the antioxidant activities of cheeses fortified with $0,0.25,0.5,0.75$, and $1 \%$ IBE were 24.21, 29.05, $54.57,66.34$, and $86.74 \%$, respectively. In particular, 0.75 and $1 \%$ IBE showed noticeable antioxidant effects compared with the control cheese. Because the FTC value is based on reduction of ferric ion, the Cheddartype cheese fortified with IBE was obviously capable of donating a single electron or hydrogen atom for the reduction reaction. The antioxidant effect evaluated by the FTC assay also decreased with longer storage periods $(\mathrm{r}=-0.105, P<0.01)$. In addition, the correlation coefficient between the total phenolic contents and FTC values was $0.713(P<0.01)$.

The results of the antioxidant activity decreased with increasing storage period and correlated with a decrease in total phenolic content indicate that the decreases were related to the fermentation or ripening process (Yoon et al., 2015). Nevertheless, the IBE-fortified Cheddar-type cheeses were demonstrated to have freeradical-scavenging, lipid peroxidation-inhibiting, and ferric-ion-reducing powers. Although longer storage of the cheeses could negatively affect their antioxidant activities, the antioxidant effects remained for up to 3 wk, especially those of lipid peroxidation inhibition and ferric in reduction.

The flavor, taste, texture, and color profiles of the samples were determined using a descriptive analysis by a trained sensory evaluation panel. The addition of IBE increased the extract-taste, bitterness, and extract-odor ratings, but did not have noticeable effects on extract odor and acid taste (Table 2). However, the addition of IBE did lower the milk-odor and milk-taste ratings. In addition, the sensory values for extract odor, acid taste, bitterness, and dark color were higher than for 
Table 2. Sensory assessment results (means \pm SD) for Cheddar-type cheeses fortified with Inula britannica flower extract (IBE) ${ }^{1}$

\begin{tabular}{|c|c|c|c|c|c|}
\hline Item & Control & $\mathrm{A}$ & B & $\mathrm{C}$ & $\mathrm{D}$ \\
\hline Extract odor & $2.24 \pm 0.00^{\mathrm{a}}$ & $2.59 \pm 0.16^{\mathrm{a}}$ & $2.74 \pm 0.19^{\mathrm{a}}$ & $2.94 \pm 0.15^{\mathrm{a}}$ & $3.00 \pm 0.17^{\mathrm{a}}$ \\
\hline Color & $5.18 \pm 0.21^{\mathrm{a}}$ & $6.65 \pm 0.18^{\mathrm{a}}$ & $6.18 \pm 0.15^{\mathrm{a}}$ & $5.53 \pm 0.21^{\mathrm{a}}$ & $5.76 \pm 0.21^{\mathrm{a}}$ \\
\hline Bitterness & $3.94 \pm 0.21^{\mathrm{a}}$ & $4.18 \pm 0.24^{\mathrm{a}}$ & $4.59 \pm 0.19^{\mathrm{a}}$ & $4.71 \pm 0.15^{\mathrm{a}}$ & $4.71 \pm 0.21^{\mathrm{a}}$ \\
\hline Milk taste & $5.12 \pm 0.2^{\mathrm{a}}$ & $4.94 \pm 0.21^{\mathrm{a}}$ & $4.47 \pm 0.19^{\mathrm{a}}$ & $4.59 \pm 0.21^{\mathrm{a}}$ & $4.18 \pm 0.21^{\mathrm{a}}$ \\
\hline Extract taste & $3.88 \pm 0.00^{\mathrm{a}}$ & $3.00 \pm 0.21^{\mathrm{a}}$ & $3.26 \pm 0.17^{\mathrm{a}}$ & $3.65 \pm 0.19^{\mathrm{a}}$ & $3.71 \pm 0.22^{\mathrm{a}}$ \\
\hline Overall quality & $4.88 \pm 0.23^{\mathrm{ab}}$ & $5.58 \pm 0.17^{\mathrm{b}}$ & $5.24 \pm 0.23^{\mathrm{ab}}$ & $4.18 \pm 0.14^{\mathrm{ab}}$ & $4.16 \pm 0.11^{\mathrm{a}}$ \\
\hline
\end{tabular}

${ }^{\mathrm{a}-\mathrm{C}}$ Averages within a row with different superscript letters are significantly different at $P<0.05$.

${ }^{1}$ Control $=$ Cheddar-type cheese made from unfortified milk; A = Cheddar-type cheese made from $0.25 \%$ IBE-fortified milk; $\mathrm{B}=$ Cheddar-type cheese made from $0.5 \%$ IBE-fortified milk; $\mathrm{C}=$ Cheddar-type cheese made from $0.75 \%$ IBE-fortified milk; $\mathrm{D}=\mathrm{Cheddar}$-type cheese made from $1 \%$ IBE-fortified milk. Scores were represented as $1=$ low, $5=$ medium, and $9=$ high.

the control cheese. In particular, the addition of 0.75 and $1 \%$ IBE increased the creaminess and decreased the graininess of the cheeses $(P<0.05)$, characteristics that give a desirable texture to the cheese. However, overall quality was as high in the cheeses fortified with 0.25 and $0.5 \%$ IBE as it was in the control cheese. The conclusion of the sensory evaluation was that the addition of IBE did not significantly affect the odor and taste of the cheeses.

In conclusion, we have investigated the effect of IBE on the physicochemical properties, sensory characteristics, and antioxidant activities of Cheddar-type cheese. The addition of IBE increased the protein and ash contents of the cheeses, with concomitant decreases in the total solids, fat content, and $\mathrm{pH}$. The total phenolic content increased with increasing concentration of IBE, but decreased over longer storage periods. Antioxidant activities were also increased by the addition of IBE, and these increase suggested biological antioxidant potential. Furthermore, IBE fortification gave a more desirable texture to the cheese and increased extract odor and taste. The cheese fortified with $0.5 \%$ IBE was available in view of sensory and antioxidant effects. Therefore, these results showed that supplementation with IBE has good potential for use in dairy products for enhancing antioxidant effects.

\section{ACKNOWLEDGMENTS}

This research was supported by Agriculture Bioindustry Technology Development Program, Ministry of Agriculture, Food and Rural Affairs (314020-2) and Priority Research Centers Program through the National Research Foundation of Korea (NRF) funded by the Ministry of Education, Science and Technology (2009-0093824).

\section{REFERENCES}

AOAC International. 2000. Official Method of Analysis. 17th ed. AOAC International, Washington, DC.

Bai, N., Z. Zhou, N. Zhu, L. Zhang, Q. Zheng, K. He, Q. Y. Zheng, and C. T. Ho. 2005. Antioxidative flavonoids from the flower of Inula britannica. J. Food Lipids 12:141-149.

Chung, H. S., L. C. Chang, S. K. Lee, L. A. Shamon, R. B. V. Breemen, R. G. Mehta, N. R. Farnsworth, J. M. Pezzuto, and A. D. Kinghorn. 1999. Flavonoid constituents of Chorizanthe diffusa with potential cancer chemopreventive activity. J. Agric. Food Chem. $47: 36-41$.

Codex. 2010. Codex Standard for Cheddar (CODEX STAN 263-1966).

da Silva, D. F., P. T. Matumoto-Pintro, L. Bazinet, C. Couillard, and M. Britten. 2015. Effect of commercial grape extracts on the cheese-making properties of milk. J. Dairy Sci. 98:1552-1562.

Gad, A. S., and M. H. A. El-Salam. 2010. The antioxidant properties of skim milk supplemented with rosemary and green tea extracts in response to pasteurization, homogenization and the addition of salts. Int. J. Dairy Technol. 63:349-355.

Giroux, H. J., G. De Gradpré, P. Fustier, C. P. Cahmpagne, D. StGelais, M. Lacroix, and M. Britten. 2013. Production and characterization of cheddar-type cheese enriched with green tea extract. Dairy Sci. Technol. 93:241-254.

Gupta, A., B. Mann, R. Kumar, and R. B. Sangwan. 2009. Antioxidant activity of Cheddar cheeses at different stages of ripening. Int. J. Dairy Technol. 62:339-347.

Han, J., M. Britten, D. St-Gelais, C. P. Champagne, P. Fustier, S. Salmieri, and M. Lacroix. 2011a. Effect of polyphenolic ingredients on physical characteristics of cheese. Food Res. Int. 44:494-497.

Han, J., M. Britten, D. St-Gelais, C. P. Champagne, P. Fustier, S Salmieri, and M. Lacroix. 2011b. Polyphenolic compounds as functional ingredients in cheese. Food Chem. 124:1589-1594.

Hassan, A. N., S. Award, and V. V. Mistry. 2007. Reduced fat process cheese made from young reduced fat cheddar cheese manufactured with exopolysaccharide-producing cultures. J. Dairy Sci 90:3604-3612.

ISO. 1998. ISO/DIS 13299:1998. Sensory analysis. Methodology: General guidance for establishing a sensory profile. International Organization for Standardization, Geneva, Switzerland.

Jung, J. E., H. J. Yoon, H. S. Yu, N. K. Lee, H. S. Jee, and H. D. Paik. 2015. Physicochemical and antioxidant properties of milk supplemented with red ginseng extract. J. Dairy Sci. 98:95-99.

Kansendossier Zuid. 2013. Opportunities in the South Korean cheese market. NL EVD International, Agentschap NL, Den Haag, the Netherlands.

Kim, J. E., A. R. Kim, and S. N. Park. 2011. A study on the stability and clinical trial for the cream containing Inula britannica flower extract. J. Soc. Cosmet. Sci. Korea 37:129-136. 
Lee, J. Y., W. I. Hwang, and S. T. Lim. 2004. Antioxidant and anticancer activities of organic extracts from Platycodon grandiflorum A, De Candolle roots. J. Ethnopharmacol. 93:409-415.

Lee, N. K., J. H. Lee, Y. J. Lee, S. H. Ahn, S. J. Eom, and H. D. Paik. 2013. Antimicrobial effect of Inula britannica flower extract against methicillin-resistant Staphylococcus aureus. Korean J. Microbiol. Biotechnol. 63:550-560.

O'Connell, J. E., and P. F. Fox. 2001. Significance and applications of phenolic compounds in the production and quality of milk and dairy products: A review. Int. Dairy J. 11:103-120.

Park, E. J., Y. Kim, and J. Kim. 2000. Acylated flavonol glycosides from the flower of Inula britannica. J. Nat. Prod. 63:34-36.

Rashidinejad, A., E. J. Birch, D. Sun-Waterhouse, and D. W. Everett. 2015. Total phenolic content and antioxidant properties of hard low-fat cheese fortified with catechin as affected by in vitro gastrointestinal digestion. LWT Food Sci. Technol. (Campinas.) 62:393-399.
Robitaille, G., H. Giroux, and M. Britten. 2004. Turbidity method to monitor the kinetics of rennet-induced coagulation of milk using a microplate reader. Milchwissenschaft 59:479-482.

Savikin, K., G. Zdunic, T. Jankovic, T. Stanojkovic, Z. Juranic, and N. Menkovic. 2009. In vitro cytotoxic and antioxidative activity of Cornus mas and Cotinus coggygria. Nat. Prod. Res. 23:1731-1739.

Seo, S. B., C. W. Ryu, G. W. Ahn, H. B. Kim, B. K. Jo, S. H. Kim, J. D. Lee, and T. Kajiuchi. 2002. Development of a natural preservative system using the mixture of chitosan-Inula helenium L. extract. Int. J. Cosmet. Sci. 24:195-206.

St-Gelais, D., J. Lessard, C. P. Champagne, and J. C. Vuillemard. 2009. Production of fresh Cheddar cheese curds with controlled postacidification and enhanced flavor. J. Dairy Sci. 92:1856-1863.

Yoon, H. J., K. A. Lee, J. H. Lee, H. J. Jin, H. J. Kim, K. T. Kim, and H. D. Paik. 2015. Effect of fermentation by Bacillus subtilis on antioxidant and cytotoxic activities of black rice bran. Int. J. Food Sci. Technol. 50:612-618. 